\title{
3 Research Square \\ Sustainable Cationic Cellulose for Highly Efficient Flocculation of Suspended Particles
}

\section{Zhen Li}

Zhejiang Sci-Tech University

\section{Wenli Gong}

Zhejiang Sci-Tech University

\section{Xuan Chen}

Zhejiang Sci-Tech University

Lin Liu ( $\square$ linliu@zstu.edu.cn )

Zhejiang Sci-Tech University https://orcid.org/0000-0001-7558-7289

\section{Ranju Meng}

Zhejiang Sci-Tech University

\section{Yanhong Ding}

Zhejiang Sci-Tech University

Juming Yao

Zhejiang Sci-Tech University

\section{Research Article}

Keywords: Cationic cellulose, bio-flocculant, turbid water purification, flocculation kinetics, charge neutralization

Posted Date: June 23rd, 2021

DOI: https://doi.org/10.21203/rs.3.rs-586249/v1

License: (c) (i) This work is licensed under a Creative Commons Attribution 4.0 International License. Read Full License 


\section{Abstract}

Sustainable, cationic cellulose bio-flocculants with various amino group contents were successfully prepared by a feasible chemical crosslinking with polyethyleneimine (PEI). The flocculation performances of diverse PEl-grafting cellulose (CE-PEI)were evaluated topurify sewage sludge treatment. Further, the preparation conditions and flocculation mechanismof CE-PEI were investigated. Benefiting from the high surface positive charges and the supramolecular structure of PEI, the results indicate that CE-PEI could remove the turbid Kaolin suspension effectively. The efficiency of CE-PEI for removing the turbid in Kaolin suspension is $98.2 \%$.Flocculation kinetic results indicated that charge neutralization was the dominant mechanism for the flocculation process. And then, the small Kaolin particles agglomerate together to form large flocs by the function of adsorbing, gathering, and enwrapping. Thus, this work not only exploits a promising application of cellulose as a bio-flocculantbut also provides a feasible approach to efficiently purify high turbidity wastewater.

\section{Introduction}

With the accelerated development of industrialization and urbanization, an enormous quantity of high turbidity wastewater was produced by the paper-making, printing and dyeing, leather,livestock, agriculture, building industries, which aggravates the process of water purification.To address the problem and create a sustainable future, a variety of technologies, such as membrane filtration(Jamshidifard et al. 2019; Zhao et al. 2020; Gao et al. 2020), adsorption(Dong et al. 2016; Vakili et al. 2019; Liu et al. 2020), oxidation(Chen et al. 2020), coagulation/flocculation (Guo et al. 2018; Zhao et al. 2021)andmicrobiological treatment(Wang et al. 2019)have been employed for water purification. Among them, flocculationis deemed to be the most favorable method for wastewater treatment becauseof its advantages of low cost, easy operation, and high efficiency for suspended colloid removal(Carvalho et al. 2018; Essandoh et al. 2019). However, severe problems of massive dosage, chemical sludge recycling, corrosively restrict the application of inorganic metal-based flocculants such as iron, aluminum, and titanium salts in turbid water purification(Zou et al. 2017; Wang et al. 2019). Whereas in fact, effective organic flocculants, for example,polyacrylamide (PAM) and its derivatives were exploited to reduce water turbidity (Chen et al. 2019; Chen et al. 2020). However, the high flocculation performance of PAM can be achieved by the addition of coagulant aids $\left(\right.$ e.g. $\left.\mathrm{CaCl}_{2}\right)$. Meanwhile, the coagulant aids resulting in a large number of loose-sludges. Moreover, organic PAM is synthesized from petrochemical resources, and cannot be biodegraded afterenvironmental restoration, resulting insecondary pollution. Thus, the design and development of sustainable and degradable bio-flocculants with high flocculation performancesisvitalfor wastewater purification.

Cellulose, as the most abundant natural bioresources, has great potential for the removal of various pollutants due to its marvelous properties of biodegradability,nontoxicity, cheap and widely available(Salehizadeh et al. 2018; Shak et al. 2018; Noor et al. 2020).It is well known that functional modification of cellulose can be easilyobtained, due to itssufficient hydroxyl groups on the surface.Thereby, a series of anionic groups such as carboxyl groups, phosphategroups, andsulfo groups, 
were introduced to improve the removal ability of cellulose for cationic dyes or heavy metal ions (Rodríguez et al. 2011; Fu et al. 2017; Wang et al. 2020). For example, Li et al.(Li et al. 2020)successfully prepared carboxylatedcellulose filters by TEMPO-mediated oxidation and presented excellent adsorption capacity for cationic dyes and heavy metal ions.Ge et al. (Ge et al. 2016)andZhang et al. (Zhang et al. 2016) prepared cationic cellulose fiber by introducing polyethyleneimine (PEI) for the removal of heavy metal ions.Besides,Dicarboxyl cellulose flocculant was manufactured by periodate oxidation for the removal of kaolin suspension assisted with $\mathrm{CaCl}_{2}$ as a coagulant (Zhu et al. 2015; Zhu et al. 2015).However, to the best of our knowledge, the employment of cationic cellulose as bio-flocculantfor the directremoval of suspended particles from wastewater has been rarely reported.

Hence,this work is to exploit the potential of cellulose bio-flocculant for efficiently removing suspended particles and reducing the turbidity of water. On the basis of abundant surface hydroxyl groups of cellulose, amine-rich cellulose bio-flocculantshave been fabricated by a feasible chemical crosslinking withbranched polyethyleneimine (PEI). The obtained cellulose bio-flocculantshave a supermolecular structure and large amounts of positively charged amine groups, exhibiting outstanding flocculation performance for suspended kaolin particles without any coagulant aid.Further, generated flocs, zeta potential, and flocculation kinetics were evaluated for understanding the flocculation mechanism.

\section{Materials And Methods}

\section{Materials.}

Cellulose $\left(M_{w}=20000\right)$ andglutaraldehyde $(25 w t \%)$ wereacquired from Macklin Biochemical Co., Ltd. (Shanghai, China). Kaolinand Polyethylenimine $(\mathrm{Mw}=600)$ was provided by Aladdin Chemical Reagent Co., Ltd. (Shanghai, China).

\section{Fabrication of cellulose bio-flocculant.}

Amine-rich cellulose bio-flocculantswere fabricated by chemical crosslinking with branched polyethyleneimine (PEI) in a heterogeneous system, according to our previous report (Chen et al. 2018). Briefly, Cellulose $(1.0 \mathrm{~g})$ was dispersedindistilled water $(100 \mathrm{~mL})$ to swell for $12 \mathrm{~h}$. Desired amounts of PEI weredoped into cellulose suspension under mechanical stirring. Crosslinking reaction was started by introducing glutaraldehyde as a cross-linking agent, under vigorous stirring at different temperatures for 3h. Finally, PEl-grafted cellulose (CE-PEI) was extracted by suction filtration and adequately washed. The surface charge density of CE-PEI was adjusted by varying the reaction conditions, correspondingly the products are denoted as CE-PEI 1, CE-PEI 2, CE-PEI3, and CE-PEI 4. The sample codes of the CE-PEI and relevant synthesis conditions were list in Table 1.

Table 1 The codes and synthesis conditions of CE-PEI and their amino contents and $\zeta$-potentials 


\begin{tabular}{|c|c|c|c|c|c|}
\hline Samples & $\begin{array}{l}\text { CE-PEI } \\
\text { पwt\%ם }\end{array}$ & $\begin{array}{c}\text { Temperature } \\
\left({ }^{\circ} \mathrm{C}\right)\end{array}$ & Glutaric dialdehyde (g) & Amino group contents $(\mathrm{mmol} / \mathrm{L})$ & $\begin{array}{c}\text { ל-potentials } \\
(\mathrm{mV})\end{array}$ \\
\hline CE-PEI 1 & $1: 1$ & 45 & 1.5 & 17.5 & 51.4 \\
\hline CE-PEI 2 & $1: 1$ & 55 & 1.5 & 12.5 & 50.3 \\
\hline CE-PEI 3 & $2: 1$ & 45 & 2 & 6.7 & 42.1 \\
\hline CE-PEI 4 & $1: 2$ & 55 & 2.5 & 1.625 & 39.7 \\
\hline
\end{tabular}

\section{Characterization.}

The surfacetopography of samples wasinvestigated by using Field Emission Scanning Electron Microscopy (FESEM, vltra55, German). Chemical crosslinking reaction was demonstrated using Fourier Transform Infrared Spectroscopy (FTIR, Nicolet 5700, Thermo, USA). Zeta potential of samples was measured using NanoSizer Nano-ZS90 (Malvern, UK). The contents of amino groups of samples were tested using titration method.CE-PEI $(0.02 \mathrm{~g})$ was added into $50 \mathrm{~mL}$ of $\mathrm{HCl}$ solution $(0.1 \mathrm{M})$ with mildly stirring for $6 \mathrm{~h}$. The consumption of $\mathrm{HCl}$ was checked by the titration of $\mathrm{NaOH}(0.1 \mathrm{M})$ with phenolphthalein as an indicator. The contents of amino groups were calculated using the following Eq. (1) (Donia et al. 2012; Sun et al. 2014).

$$
\text { Amino group contents }\left(\frac{\mathrm{mmol}}{\mathrm{g}}\right)=\frac{\left(\mathrm{C}_{i}-\mathrm{C}_{e}\right) \times 50}{0.02}(1)
$$

where $\mathrm{C}_{\mathrm{i}}$ and $\mathrm{C}_{\mathrm{e}}$ are initial concentration and equilibrium concentration of $\mathrm{HCl}$ solution $(\mathrm{mol} / \mathrm{L})$, respectively.

\section{Flocculation performance for suspended particles}

The flocculation performance of CE-PEI for suspended particles from wastewater was assessed, by using Kaolin standard suspension with $500 \mathrm{mg} / \mathrm{L}$ as a model. Briefly, CE-PEl was added into $40 \mathrm{~mL}$ of Kaolin suspension and stirred at $200 \mathrm{rpm}$ for $1 \mathrm{~min}$. Finally, a slow stirring at $50 \mathrm{rpm}$ for $5 \mathrm{~min}$ was used to floc aggregation. Subsequently, setting for sedimentation without stirring.After sedimentation,the change of turbidity and zeta potential of the system was tested using Turb 550 turbiditor and NanoSizer Nano-ZS90. The flocs size was determined using Mastersizer 2000 (Malvern). The setting height was measured by adding $100 \mathrm{~mL}$ Kaolin suspension into abeaker $(1 \mathrm{~L})$ cylinder with optimal dosage of cellulose bioflocculants at $5 \mathrm{~min}$ intervals. The effects of CE-PEI dosages (0-10 mg), suspension pH values (3-11), and settling time (0-30 $\mathrm{min})$ on flocculation behavior were investigated in detail. Each test was performed three times.

\section{Result And Discussion}

\section{Characterization of cellulosebio-flocculant}

On the basis of the abundant surface hydroxyl groups of cellulose, cellulosebio-flocculantcan be easily fabricated by crosslinking reaction with PEI and glutaraldehyde (Scheme 1). The grafting reaction is verified by FTIR spectra in Fig 1a.After grafting, the characteristic peak of cellulosefrom $3349 \mathrm{~cm}^{-1}$ shifts to $3417 \mathrm{~cm}^{-1}$ in CE-PEI 
associated with the overlapping of $\mathrm{O}-\mathrm{H}$ and N-H stretching vibration (Cheng et al. 2014). Three new peaks at 1656, 1579 and $1430 \mathrm{~cm}^{-1}$ appear, corresponding to bending vibration of $\mathrm{N}-\mathrm{H}$, stretching vibration of $\mathrm{C}=\mathrm{N}$ and $\mathrm{C}-\mathrm{N}$, respectively (Park et al. 2014). This indicated the successful Schiff base reaction between aldehyde group (-COH) of glutaraldehyde and- $\mathrm{NH}_{2}$ of PEI. Moreover, the typical C-O-C stretching vibrations of cellulose polysaccharide at $1057-1160 \mathrm{~cm}^{-1}$ shift to a largerwavenumber,indicating thatthe formation of new ether bondbetweenglutaraldehyde and cellulose. In addition, the occurrence of $-\mathrm{CH}_{2}$ - stretching vibrations at 2923 and $2848 \mathrm{~cm}^{-1}$ and $\mathrm{C}-\mathrm{H}$ bending vibration at $771 \mathrm{~cm}^{-1}$ also confirms the successful grafting of PEI.The content of amino groups and the surface zeta potential of CE-PEI can be controlled by adjusting the reaction conditions, including the ratio of cellulose and PEI, reaction temperature, and glutaraldehyde amount. Fig 1 band Table 1 showthat the amino group content and the zeta potential of CE-PEI 1 presented the maximum value of $17.5 \mathrm{mmol} / \mathrm{g}$ and 51.4 $\mathrm{mV}$, revealing a positively charged surface due to the existence of multiple amino groups. The morphology of cellulose and CE-PEI was observed using FESEM and displayed an irregular shape (Fig 1c and d). The surface of cellulose is smooth. After PEI modification, many micro-crackswere found along withthe cellulose microfibers, whichcan facilitate the adsorption of pollutants.

\section{Flocculation performanceof CE-PEI for Kaolin particles}

To understand the relationship of surface property-activity, four bio-flocculants with different amino group content and zeta potential were employed to assess the removal of Kaolin particles.Here, the effects of CE-PEI dosage, $\mathrm{pH}$ value, setting time on flocculation performances were investigated in detail. Variation in turbidity, zeta potential, floc size, interface height of system was determined.

\section{Effect of CE-PEI dosage}

The effect of CE-PEI dosage on the residual turbidity and average floc size of the Kaolin suspension wa: studied and shown in Fig 2. In Fig 2a, the turbidity of the suspension all declined sharply with the increase of CE PEI dosages until minimum values at corresponding optimal dosage, subsequently a tiny increase. Compared wit] CE-PEI 4, the turbidity removal efficiencies of CE-PEI 1, CE-PEI 2, and CE-PEI 3 are higher because of active site: increases with the amount of amino group. Theturbidity of Kaolin suspension significantlyreduced from initial tı $480 \mathrm{NTU}$ to $8.7 \mathrm{NTU}$ for CE-PEI 1 with $6 \mathrm{mg}$. The removal efficiency approached a maximum value of 98.2\% higher than that of CE-PEI 2 (95.7\%) and CE-PEI 3 (97.1\%). However, the turbidity tiny increased when the dosag! was $10 \mathrm{mg}$, which revealed that charge neutralization is dominant during the flocculation process. Positivel: charged CE-PEI neutralizes the surface negative charge in Kaolin particles to generate insoluble floc. Whereafter flocs further aggregate, grow, and settle down, consequently resulting in turbidity reduction. Nonetheless excessive flocculants lead to the destabilization of flocs due to the electrostatic repulsion betweenthe initia flocs, which isfurther demonstrated by the average floc size.

Fig $2 \mathrm{~b}$ shows the change of the average floc size as the increase of CE-PEI dosages.Increasing CE-PE dosages from 2 to $8 \mathrm{mg}$, the average floc size remarkably increased, subsequently decreased when the dosag' 
reaches $10 \mathrm{mg}$. Maximum floc sizes produced by CE-PEI 1, CE-PEI 2, CE-PEI 3, and CE-PEI 4 reached $48.6 \pm 0.9$ $45.0 \pm 1.4,38.7 \pm 2.6$, and $36.4 \pm 1.9 \mu \mathrm{m}$, respectively, which gradually enlargedwith the increase of amino grou] contents of four CE-PEI.Adding CE-PEI, positively charged flocculants have been transferred from the solutio] phase to the surface of Kaolin particles to generate insolubleflocculant-kaolin complexesthrough chargr neutralization. The flocculant-kaolin complexes still have vacant active sites for absorbing other Kaolin particle: which can produce bridging actions between Kaolin particles, consequently, forming larger flocs with a 3D networ] structure.Simultaneously, the flocs with a large size further capture small flocs and residual kaolin particles in thı system via the capture effect and sweeping(Li et al. 2015). All these resulted in the optimal rate value for thi precipitation of particles.Excessive flocculants might impart a positive electric charge to Kaolin particles to causı electrostatic repulsion. Additionally, at higher flocculants dosages could cover most of the available sites on thı suspended particles, leading to ignorable bridging action. Thus, the floc size decreased.

\section{Effect of $p H$}

Fig 3shows the variation in turbidity and zeta potential of the suspension as a function of $\mathrm{pH}$ values. Introducin! CE-PEI into suspension, residual turbidity of the system was declined at pH 3-7 butincreased when pHincrease from 8 to 12(Fig 3a). Moreover, CE-PEI 1 displayed the best Kaolin removal of CE-PEI can reach94.9\%at pF 7.0.Notably, Kaolin standard suspensions are negatively charged within the entire pH range (Hosseinpour et a] 2020). The zeta potential of the system became increases and then decreases with increasing pH values(Fig 3b) Increased zeta potential could be because that the electronegative charges on the Kaolin particle surface werı neutralized by the electropositive CE-PEI. The decrease might be due to the deprotonation of amino groups, wher the negative surface charges on the CE-PEI increased at alkaline conditions. The maximum zeta potential of thr system was found at pH 5.0. Moreover, it is clearly that the zeta potential of the system approached zero at pF 6.4-7.0 with different CE-PEI flocculants, revealing that thecharge neutralization effectperformed a dominant rolı in the flocculation process. By contrast, CE-PEI 4 showed higher turbidity reduction and zeta potential under a] alkaline condition which revealed that contrasted with charge neutralization, bridging action and/or adsorptio] played a role in the flocculation process.

\section{Effect of settling time}

The time dependence of settling property was investigated turbidity and settling height of Kaolin suspension. As shown in Fig 4a,the turbidity of Kaolin suspension sharply decreased within the first 5 min, the reduction slightly fluctuated in the range of 78.3-85.0\% corresponding to four CE-PEI flocculants with different surfaces properties. Fig $4 \mathrm{~b}$ further displayed a rapid sedimentation process in view of the remarkable decline in interface height. Moreover, higher amino group content, faster settling velocity. These results showed that the sedimentation of most flocs was accomplished in a short time. With anincreasing settling time from 5 to $30 \mathrm{~min}$, remnant turbidity decreased slowlybecause thegrowth of small flocs is slowly adversed to settlement. The best removal efficiency of the Kaolin turbidity of CE-PEI reached $98.2 \%$ in $30 \mathrm{~min}$. 
Flocculation kinetics and mechanism

Table 2 The rateconstants and correlation coefficients (R2) for flocculation of Kaolin by CE-PEI at different initial concentrations

\begin{tabular}{|c|c|c|c|c|}
\hline \multirow[t]{2}{*}{ Flocculant doses (ppm) } & \multicolumn{2}{|c|}{ Kinetics of aggregation of particles } & \multicolumn{2}{|c|}{ Frequency of collisions of particles } \\
\hline & $k_{1}\left(\times 10^{-14}\right.$ count $\left.^{-1} \mathrm{~s}^{1}\right)$ & $k_{2}\left(\times 10^{-3} \mathrm{~s}^{1}\right)$ & $k\left(\times 10^{-14} \mathrm{~s}^{-1}\right)$ & $R^{2}$ \\
\hline 50 & 1.43 & 11.03 & 1.08 & 0.95602 \\
\hline 100 & 2.02 & 24.91 & 1.44 & 0.96712 \\
\hline 150 & 143.89 & 4.08 & 10.51 & 0.98228 \\
\hline 200 & 192.37 & 79.78 & 8.96 & 0.9815 \\
\hline 250 & 123.26 & 85.15 & 6.33 & 0.95766 \\
\hline
\end{tabular}

To further explain the flocculationmechanism, flocculation kinetics of representative CE-PEI 1 was investigated through blending flocculants $(2-10 \mathrm{mg}$ ) into $40 \mathrm{~mL}$ of Kaolin suspension with rapid stirring (200 rpm) and then settling for $30 \mathrm{~min}$. The supernatant was collected for kinetic analysis. The flocculation process is a mainly bimolecular reaction, thereby, the aggregation and collision of particles were determined according to the flocculation kinetic models, expressed as $\mathrm{Eq}(2)$ and $\mathrm{Eq}(3)$, respectively.

$$
\begin{aligned}
& \frac{d_{\left(N_{t} / N_{0}\right)}}{d_{t}}=-N_{0} k_{1}\left(\frac{N_{t}}{N_{0}}\right)^{2}+k_{2} \frac{N_{t}}{N_{0}} \\
& \sqrt{\frac{N_{0}}{N_{t}}}=1+\frac{1}{2} k N_{0} t
\end{aligned}
$$

where $N_{t}$ is the concentration of kaolin particles at $t(\mathrm{~s}) . N_{0}$ is the initial concentration of kaolin particles, which can be calculated by considering the particle diameter $(1.2 \mu \mathrm{m})$ and density of kaolin $\left(2.6 \mathrm{~g} \mathrm{~cm}^{-3}\right) . \mathrm{k}_{1}\left(\mathrm{~s}^{-}\right.$ ${ }^{1}$ ) and $k_{2}\left(\mathrm{~s}^{-1}\right)$ is the kinetic constant for the particle aggregation and aggregate breakage, respectively. $k\left(\mathrm{~s}^{-1}\right)$ is the rate constant for particle collisions.

The theoretically simulated curves were fitted and the results are shown in Fig 5 and Table 2.The concentration of Kaolin particles was shown a remarkable reduction at the initial $60 \mathrm{~s}$ when CE-PEI 1 was added to the system, then gradually declined or remained stable with increased flocculation time, which revealed that the excellent adsorption-flocculation-sedimentation of CE-PEI for Kaolin, as show in Fig 5a. The concentration of Kaolin particles at a lower dosage (50-100 mg/L) and a higher dosage (250 mg/L) were higher than those at the intermediate dosage (150-200 mg/L). It's due to the number of positive charges on CE-PEI 1 was not enough to completely neutralize the negative charges on the surface of Kaolin particles at the low dosage. Andexcessive 
dosage led toelectrostatic repulsion and cage effect caused by CE-PEI at higher dosages covering most of the available sites on each particle. Thus, the rate for aggregation of Kaolin particles decreased. As shown in Table 2, the rate constant $k_{1}$ and $k_{2}$ for particleaggregation and aggregate breakage increased with increasing flocculant dosages from 50 to $200 \mathrm{mg} /$ Lexcept for $k_{2}$ at $150 \mathrm{mg} / \mathrm{L} . \mathrm{k}_{1}$ and $\mathrm{k}_{2}$ obtained with $250 \mathrm{mg} / \mathrm{Lwere} 123.26 \times 10^{-14} \mathrm{~s}^{-1}$ and $85.15 \times 10^{-3} \mathrm{~s}^{-1}$, respectively. This shows that the floc generated at high dosage was harder than floc formed at low dosage due to the steric and electrostatic repulsion forces among particles. Moreover, the minimum $k_{2}$ of $4.08 \times 10^{-3} \mathrm{~s}^{-1}$ was found at the dosage of $150 \mathrm{mg} / \mathrm{L}$, which indicated a moderate CE-PEI could improve the floc strength and stability. Further, the maximum kof $10.51 \times 10^{-14} \mathrm{~s}^{-1}$ was also found at $150 \mathrm{mg} / \mathrm{L}$ whichindicated that collision between particles was effective at the optimal dosage,and increase or reduction dosages will cause the decrease in the value of $k$ (Peng et al. 2010). At a low dosage, the interaction including charge neutralization and bridging action between CE-PEI and Kaolin particles was very weak,it's due to the low-density positive charge in the system, leading tolower $k$. There were significant positive correlations between the value of $\mathrm{k}$ and the dosage of CE-PEI resulting from more positive charges and adsorption sites on the flocculants, which is beneficial for accelerating the molecular collisions. However, an excess of CE-PEI caused steric and static repulsion and reduced the number of effective junction points causing decreased $k$.

Therefore, according to the analysis on the flocculation performances and flocculation kinetics, the assumed flocculation mechanism of CE-PEI for Kaolin particles was proposed and illustrated in Fig. 6.The stabilization of Kaolin suspension was destroyed by the addition of positively charged CE-PEI via charge neutralization, and numerous small aggregates generated. These aggregates collided and further agglomerated with regional electrostatic attraction and supramolecular structure of CE-PEI through bridging action. These larger netlike aggregates could further capture the suspended Kaolin particles by capture and sweeping effect, forming heavier and denser flocs, finally sedimentation.

\section{Conclusion}

In this work, a series of sustainable cationic cellulose bio-flocculants with various amino group contents were successfully prepared by a feasible chemical crosslinking with PEI and glutaraldehyde. The flocculation performances of diverse CE-PEI bio-flocculants were evaluated to purify turbid Kaolin suspension. Further, the flocculation kinetics and flocculation mechanism were investigated. Benefiting from the high surface positive charges and supramolecular structure, CE-PEI bio-flocculants with amino group contents of $17.5 \mathrm{mmol} / \mathrm{g}$ displayed the best turbidity removal efficiency with the dosage of 0.15 $\mathrm{mg} / \mathrm{mL}$, sedimentation time of $30 \mathrm{~min}$ at $\mathrm{pH}$ 7.0. The residual turbidity of Kaolin suspension decreased from the initial 480 NTU to 8.6 NTU, a 98.2\% reduction. Flocculation kinetic results illustratedthat the interaction of aggregation and collision between CE-PEI bio-flocculants and Kaolin particles was sufficient for the flocculation process at the optimal CE-PEI dosage. Moreover, charge neutralization was the dominant mechanism for the flocculation of CE-PEI on Kaolin. Thus, this work not only exploits a 
promising application of cellulose as a bio-flocculantbut also provides a feasible approach to efficiently purify high turbidity wastewater.

\section{Declarations}

\section{Acknowledgments}

The work was financially supported by the National Natural Science Foundation of China (51672251), and 521 Talent Project of Zhejiang Sci-Tech University.

Conflicts of interest

All authors declared no conflict of interest.

Availability of data and material

The datasets used or analyzed during the current study are available from the first author on reasonable request.

Code availability

Not applicable

Authors' contributions

Zhen Li: Investigation, Data curation, Writing-original draft. Wenli Gong: Investigation, Data curation. Xuan Chen: Methodology. Ranju Meng: Format and layout. Yanhong Ding:Characterization. Lin Liu: Supervision, Review \& editing, Funding acquisition. Juming Yao: Conceptualization, Writing-review \& editing.

Ethics approval

Not applicable

Consent to participate

Not applicable

Consent for publication

Not applicable

\section{References}

1. Carvalho AJF, Trovatti E, Casale CA (2018) Polystyrene and cellulose nanofibril composites: Fiber dispersion driven by nanoemulsion flocculation in the presence of a fiber or nanofiber suspension. $J$ Mol Liq 272:387-394. https://doi.org/10.1016/j.molliq.2018.09.089 
2. Chen FJ, Jin XK, Jia DD, Cao YL, Duan HM, Long MQ (2020) Efficient treament of organic pollutants over Cds/graphene composites photocatalysts. Appl Surf Sci 504:144422. https://doi.org/ 10.1016/j.apsusc.2019.144422

3. Cheng M, Qin Z, Liu Y, Qin Y, Li T, Chen L, Zhu M (2014) Efficient extraction of carboxylated spherical cellulose nanocrystals with narrow distribution through hydrolysis of lyocell fibers by using ammonium persulfate as an oxidant. J Mater Chem A 2:251-258.

https://doi.org/10.1039/C3TA13653A

4. Chen J, Xu XJ, Nie R, Feng L, Li XH, Liu BZ (2020) Chitosan modified cationic polyacrylamide initiated by $\mathrm{UV}-\mathrm{H}_{2} \mathrm{O}_{2}$ for sludge flocculation and new insight on the floc characteristics study. Polymers-Basel 12(11):2738-2746. https://doi.org/10.3390/polym12112738

5. Chen X, Liu L, Luo ZH, Shen JY, Ni QQ, Yao JM (2018) Facile preparation of a cellulose-based bioadsorbent modified by hPEl in heterogeneous system for high-efficiency removal of multiple types of dyes. React Funct Polym 125:77-83. https://doi.org/10.1016/j.reactfunctpolym.2018.02.009

6. Chen Y, Tian GW, Zhai BY, Zhang HL, Liang YN, Liang HB (2019) Cationic starch-grafted-cationic polyacrylamide based graphene oxide ternary composite flocculant for the enhanced flocculation of oil sludge suspension. Compos Part B-Eng 177:107416.

https://doi.org/10.1016/j.compositesb.2019.107416

7. Dong LJ, Zhu ZL, Qiu YL, Zhao JF (2016) Removal of lead from aqueous solution by hydroxyapatite/manganese dioxide composite. Front. Environ. Sci Eng 10:28-36. https://doi.org/10.1007/s11783-014-0722-5

8. Donia AM, Atia AA, Abouzayed FI (2012) Preparation and characterization of nanomagnetic cellulose with fast kinetic properties towards the adsorption of some metalions. Chem Eng J 191:2230. https://doi.org/10.1016/j.cej.2011.08.034

9. Essandoh M, Garcia RA, Nieman CM (2018) Chemical and enzymatic protein cross-linking to improve flocculant properties. ACS Sustain Chem Eng 6(10):12946-12952.

https://doi.org/10.1021/acssuschemeng.8b02395

10. Fu Q, Sutherland A, Gustafsson E, Ali MM, SoleymaniOrcid L, Pelton R (2017) Relating redox properties of polyvinylamine-g-tempo/laccase hydrogel complexes to cellulose oxidation. Langmuir 33(32):7854-7861. https://doi.org/10.1021/acs.langmuir.7b01460

11. Gao LF, Li C, Huang WC, Mei S, Lin H, Ou Q, Zhang Y, Guo J, Zhang F, Xu SX, Zhang H (2020) Mxene/polymer membranes: synthesis, properties, and emerging applications. Chem Mater 32(5):1703-1747. https://doi.org/10.1021/acs.chemmater.9b04408

12. Ge H, Huang H, Xu M, Chen Q (2016) Cellulose/poly (ethylene imine) composites as efficient and reusable adsorbents for heavy metal ions. Cellulose 23:2527-2537. https://doi.org/10.1007/s10570016-0973-3

13. Guo WJ, Fu ZY, Wang H, Liu SS, Wu FC, Giesy JP (2018) Removal of antimonate (Sb(V)) and antimonite $(\mathrm{Sb}(\mathrm{III}))$ from aqueous solutions by coagulation-flocculation-sedimentation (CFS): 
Dependence on influencing factors and insights into removal mechanisms. SCI Total Environ. 644:1277-1285. https://doi.org/10.1016/j.scitotenv.2018.07.034

14. Hosseinpour FZ, Fatehi P (2020) Carboxymethylated cellulose nanocrystals as clay suspension dispersants: effect of size and surface functional groups. Cellulose 27: 3759-3772. https://doi.org/10.1007/s10570-020-03024-w

15. Jamshidifard S, Koushkbaghi S, Hosseini S, Rezaei S, Karamipour A, Jafari A, Irani M (2019) Incorporation of UiO-66- $\mathrm{NH}_{2}$ MOF into the PAN/chitosan nanofibers for adsorption and membrane filtration of $\mathrm{Pb}(\mathrm{II}), \mathrm{Cd}(\mathrm{II})$ and $\mathrm{Cr}(\mathrm{VI})$ ions from aqueous solutions. J Hazard Mater 368:10-20. https://doi.org/10.1016/j.jhazmat.2019.01.024

16. Li C, Ma HY, Venkateswaran S, Hsiao BS (2020) Highly efficient and sustainable carboxylated cellulose filters for removal of cationic dyes/heavy metals ions, Chem Eng $J$ 389:123458. https://doi.org/10.1016/j.cej.2019.123458

17. Li HJ, Cai T, Yuan B, Li RH, Yang H, Li A (2015) Flocculation of both kaolin and hematite suspensions using the starch-based flocculants and their floc properties. Ind Eng Chem Res 54(1):59-67. https://doi.org/10.1021/ie503606y

18. Liu M, Jia L. D, Zhao Z. X, Han Y, Li YX, Peng QM, Q. Zhang R (2020) Fast and robust lead (II) removal from water by bioinspired amyloid lysozyme fibrils conjugated with polyethyleneimine (PEI). Chem Eng J 390:124667-124676. https://doi.org/10.1016/j.cej.2020.124667

19. Noor MHM, Ngadi N, Inuwa IM, Opotu LA, M. Nawawi GM (2020) Synthesis and application of polyacrylamide grafted magnetic cellulose flocculant for palm oil wastewater treatment. J Environ Chem Eng 8(4):104014. https://doi.org/10.1016/j.jece.2020.104014

20. Park JH, Choi HM, Oh KW (2014) Simultaneous crosslinking and cationization of cotton cellulose by using dialdehyde and choline chloride: comparison between the pad-dry-cure and microwave irradiation process. Cellulose 21:3107-3119. https://doi.org/10.1007/s10570-014-0326-z

21. Peng P, Garnier G (2010) Effect of cationic polyacrylamide adsorption kinetics and ionic strength on precipitated calcium carbonate flocculation. Langmuir 26(22):16949-16957. https://doi.org/10.1021/la103410j

22. Rodríguez K, Renneckar S, Gatenholm $P$ (2011) Biomimetic calcium phosphate crystal mineralization on electrospun cellulose-based scaffolds. ACS Appl Mater Inter 3(3):681-689. https://doi.org/10.1021/am100972r

23. Salehizadeh H, Yan N, Farnood R (2018) Recent advances in polysaccharide bio-based flocculants. Biotechnol Adv. 36(1): 92-119. https://doi.org/10.1016/j.biotechadv.2017.10.002

24. Shak KPY, Pang YL, Mah SK (2018) Nanocellulose: Recent advances and its prospects in environmental remediation. Beilstein J Nanotechnol 9:24792498. https://doi.org/10.3762/bjnano.9.232

25. Sun X, Yang L, Li Q, Zhao J, Li X, Wang X, Liu H (2014) Amino-functionalized magnetic cellulose nanocomposite as adsorbent for removal of $\mathrm{Cr}(\mathrm{VI})$ : synthesis and adsorption studies. Chem Eng $\mathrm{J}$ 241:175-183. https://doi.org/10.1016/ j.cej.2013.12.051

Page $11 / 15$ 
26. Vakili M, Deng S, Cagnetta G, Wang W, Meng PP, Liu DC, Yu G (2019) Regeneration of chitosan-based adsorbents used in heavy metal adsorption: A review. Sep Purif Technol 224:373-

387. https://doi.org/10.1016/j.seppur.2019.05.040

27. Wang H, Ji XF, Ahmed M, Huang FH, Sessler JL (2019) Hydrogels for anion removal from water, J Mater Chem A 7:1394-1403. https://doi.org/10.1039/C8TA1028 6D

28. Wang N, Ouyang XK, Yang LY, A. Omer M (2017) Fabrication of a magnetic cellulose nanocrystal/metal-organic framework composite for removal of $\mathrm{Pb}$ (ii) from water. ACS Sustain Chem Eng 5(11):10447-10458. https://doi.org/10.1021/acssuschemeng.7b02472

29. Wang Q, Xie D, Chen JJ, Liu G, Yu MG (2020) Facile fabrication of superhydrophobic and photoluminescent tempo-oxidized cellulose-based paper for anticounterfeiting application. ACS Sustain Chem Eng 8(35):13176-13184. https://doi.org/10.1021/acssuschemeng.0c01559

30. Zou YD, Wang XG, Wu F, Yu SJ, Hu YZ, Song WC, Liu YH, Wang HQ, Hayat T, Wang XK (2017) Controllable synthesis of Ca-Mg-Al layered double hydroxides and calcined layered double oxides for the efficient removal of U(vi) from wastewater solutions. ACS Sustain Chem Eng 5(1):11731185. https://doi.org/10.1021/acssuschemeng.6b02550

31. Zhao CL, Zhou JY, Yan Y, Yang LW, Xing GH, Li HY, Wu P, Wang MY, Zheng HL (2021) Application of coagulation/flocculation in oily wastewater treatment: A review. Sci Total Environ 761:142795 https://doi.org/10.1016/j.scitotenv.2020.142795

32. Zhao DL, Japip S, Zhang Y, Weber M, Maletzko C, Chung T. S (2020) Emerging thin-film nanocomposite (TFN) membranes for reverse osmosis: A review. Water Res 173:115557. https://doi.org/10.1016/j.watres.2020.115557

33. Zhang N, Zang GL, Shi C, Yu HQ, Sheng GP (2016) A novel adsorbent TEMPO mediated oxidized cellulose nanofifibrils modifified with PEl: preparation, characterization, and application for Cu (II) removal, J Hazard Mater 316:11-18. https://doi.org/10.1016/j.jhazmat.2016.05.018

34. Zhu HC, Zhang Y, Yang XG, Liu HY, X. Zhang M, Yao JM (2015) An eco-friendly one-step synthesis of dicarboxyl cellulose for potential application in flocculation. Ind Eng Chem Res 54:28252829 https://doi.org/10.1021/ie503020n

35. Zhu HC, Zhang Y, Yang XG, Liu HY, Shao L, Zhang XM, Yao JM (2015) One-step green synthesis of non-hazardous dicarboxyl celluloseflocculant and its flocculation activity evaluation. J Hazard Mater 296:1-8. https://doi.org/10.1016/j.jhazmat.2015.04.029

\section{Figures}



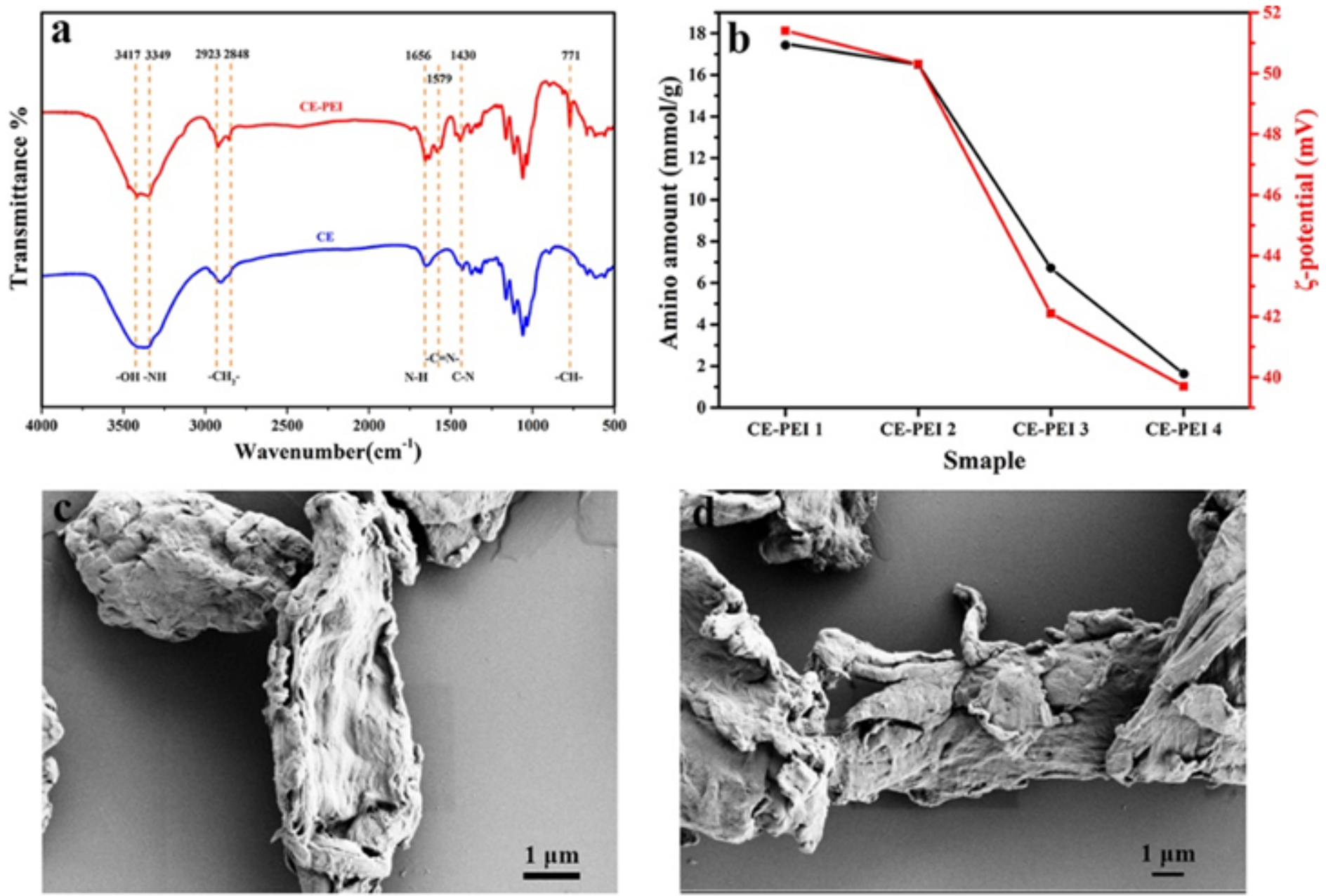

Figure 1

FT-IR spectra of the CE and CE-PEI (a). Amino group contents and zeta potentials of different CE-PEI (b). FESEM images of the original CE (c) and CE-PEI (d)
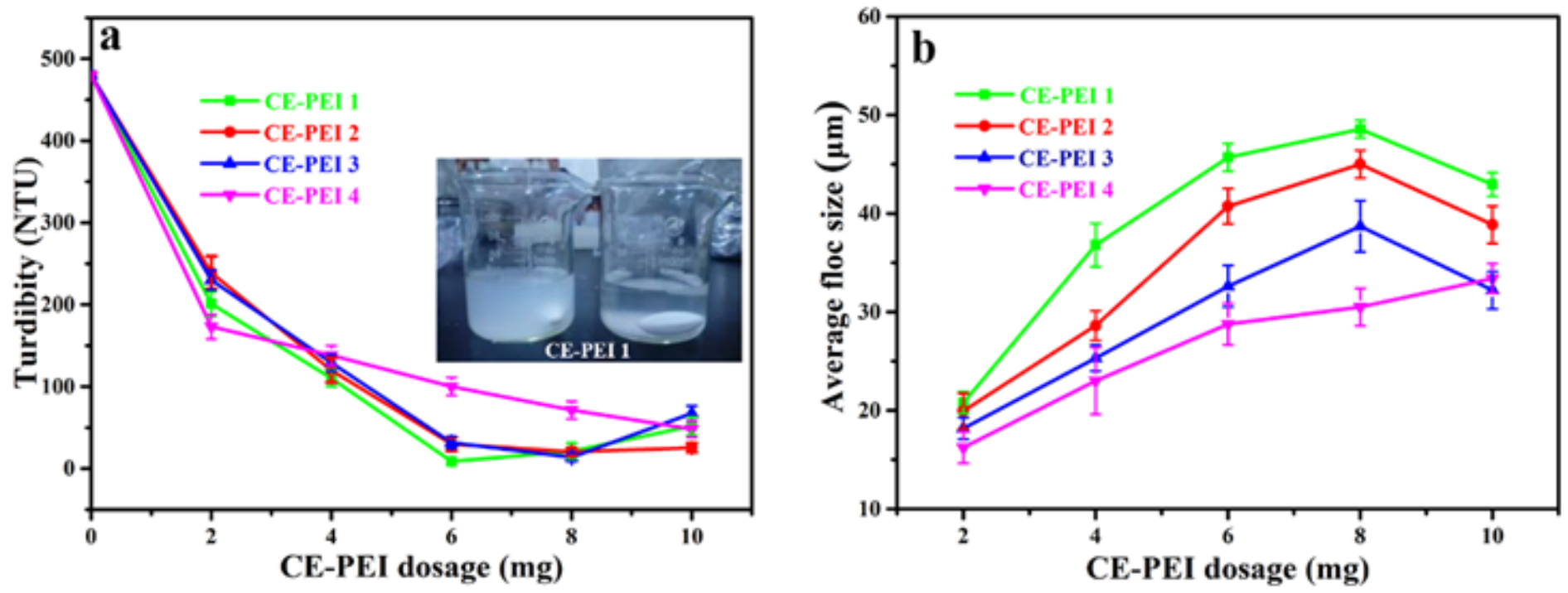

Figure 2 
Effect of CE-PEl dosages on the turbidity (a) and floc size (b)
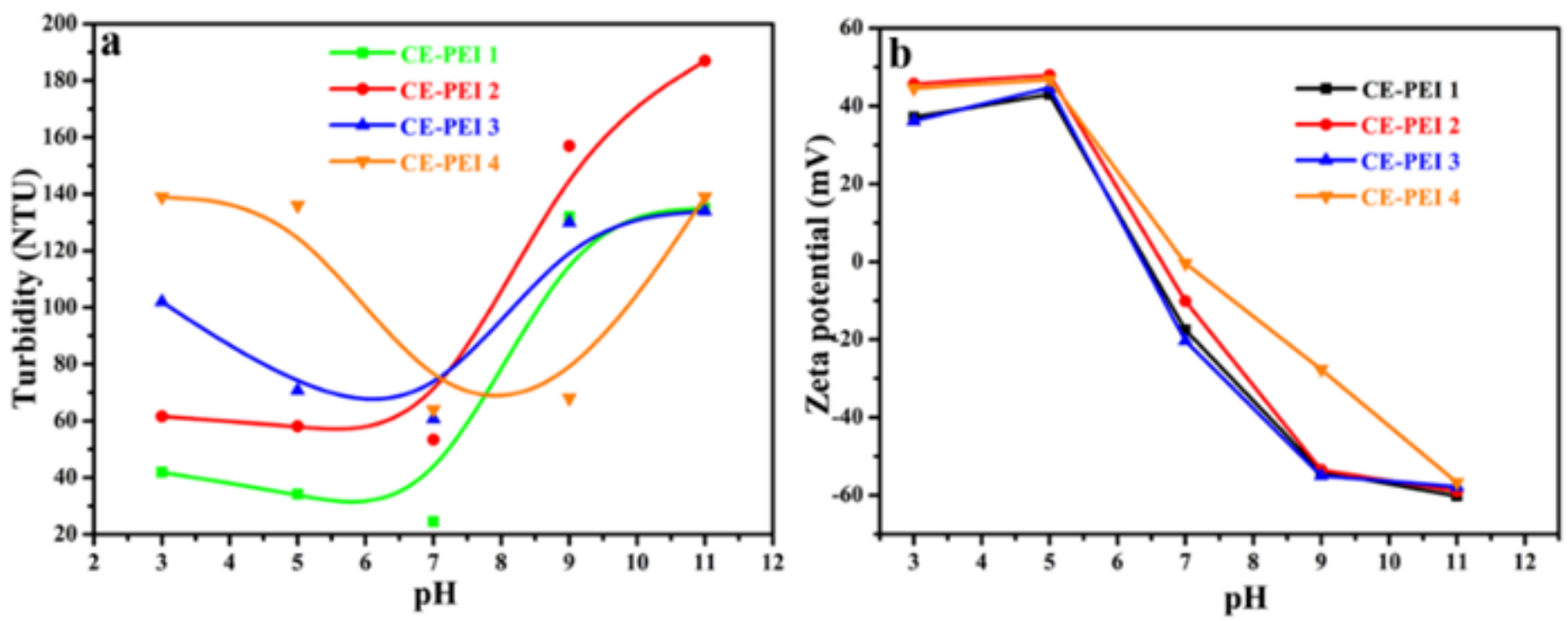

Figure 3

Effect of $\mathrm{pH}$ on the turbidity (a)and Zeta potential (b) of kaolin solution
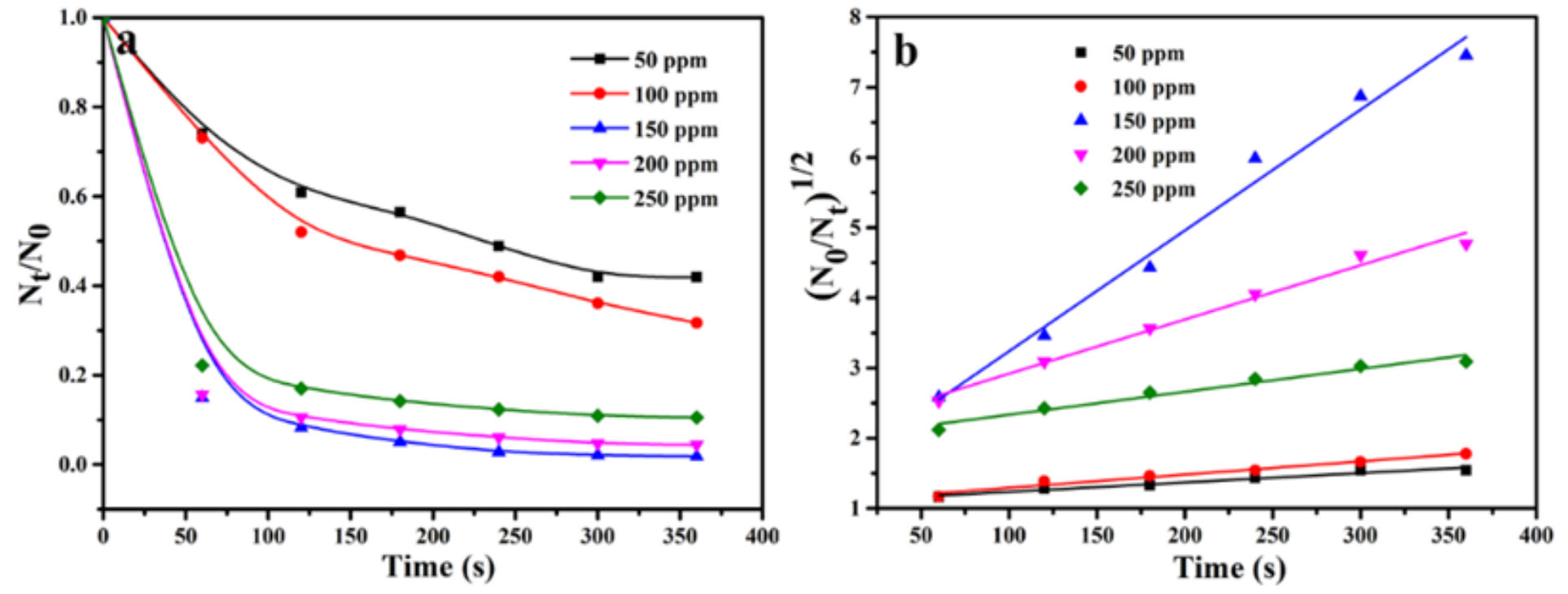

Figure 4

Effect of time on the turbidity (a) and of interface height (b) kaolin solution 

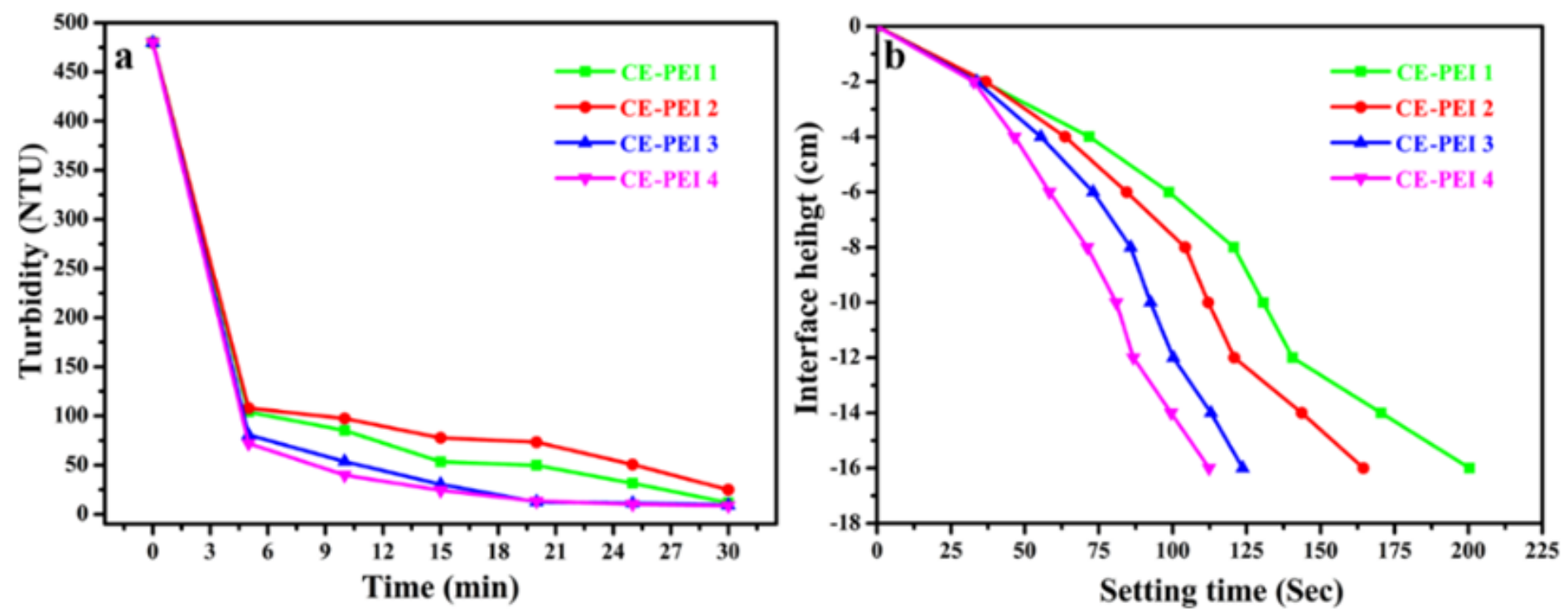

Figure 5

Kinetic curves of flocculation of Kaolin by CE-PEl at different initial concentrations

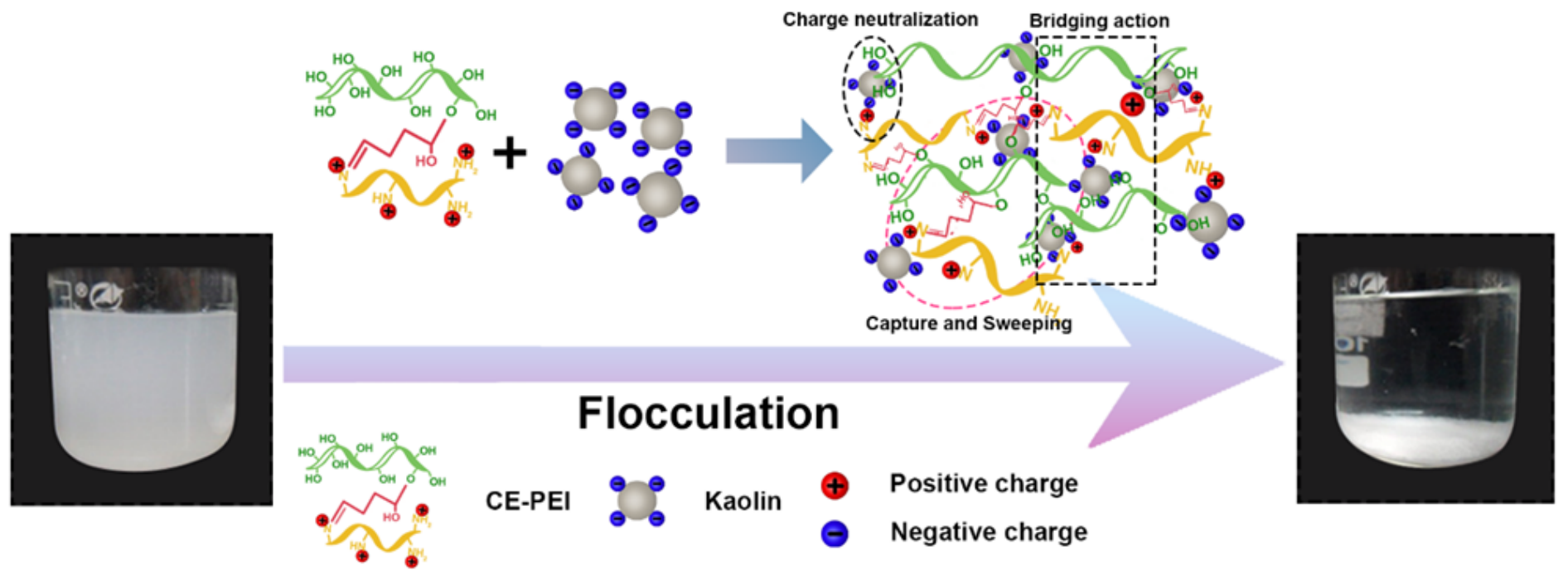

Figure 6

Proposed flocculation mechanism of CE-PEl for Kaolin particles 